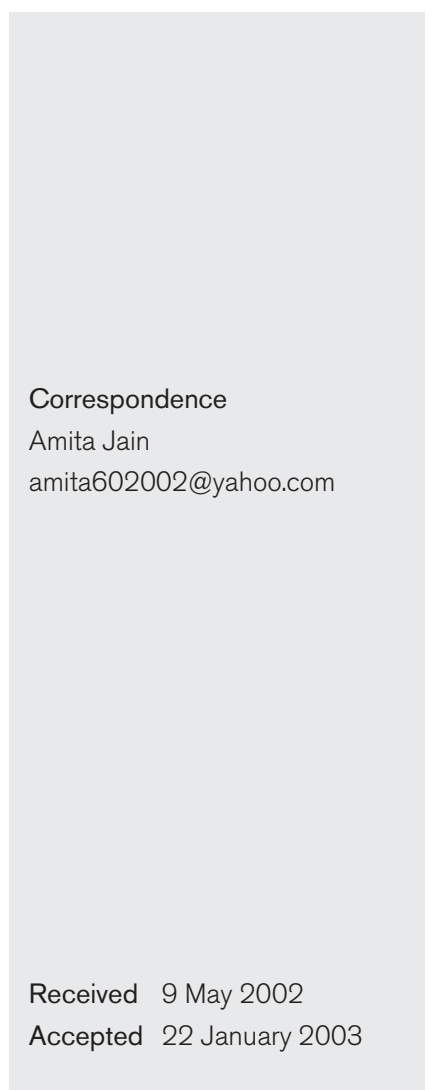

\title{
Prevalence of extended-spectrum $\beta$-lactamase- producing Gram-negative bacteria in septicaemic neonates in a tertiary care hospital
}

\author{
Amita Jain, ${ }^{1}$ Indranil Roy, ${ }^{1}$ Mahendra K. Gupta, ${ }^{1}$ Mala Kumar ${ }^{2}$ \\ and S. K. Agarwal ${ }^{1}$ \\ Departments of Microbiology ${ }^{1}$ and Paediatrics ${ }^{2}$, King George's Medical College, Lucknow, UP - \\ 226 003, India
}

\begin{abstract}
The present study was undertaken to investigate the high incidence of multiresistant Gram-negative bacilli causing neonatal septicaemia. Samples of neonatal blood from 728 suspected cases were obtained in brain heart infusion broth with sodium polyanethol sulfonate. All Gram-negative rods isolated were subsequently subjected to routine antimicrobial susceptibility testing and tests for extended-spectrum $\beta$-lactamase (ESBL) production, as per NCCLS recommendations. ESBL was detected in $86.6 \%$ of Klebsiella spp., $73.4 \%$ of Enterobacter spp. and $63.6 \%$ of Escherichia coli strains. It was also observed that $74.4-80.9 \%$ of these ESBL producers were resistant to cefotaxime and $47 \cdot 6-59.5 \%$ were resistant to ceftazidime in routine susceptibility testing. Some ESBL producers (36.3-61.5\%) were found to be susceptible to either or both cephalosporins used in this study. It is concluded that indiscriminate use of third-generation cephalosporins may be responsible for the selection of ESBL-producing multiresistant strains in the neonatal intensive-care unit (NICU).
\end{abstract}

\section{INTRODUCTION}

Resistance to antimicrobials is more common where they are used with greatest frequency (Ellner et al., 1987); intensivecare units are one of those places. In this study, we focused on the neonatal intensive-care unit (NICU). We chose septicaemic neonates as the subjects of our study, as we observed that the positivity rate of blood cultures was appreciably high, with a predominance of multiresistant Gram-negative rods among the isolates. The extensive use of third-generation cephalosporins as first-line drugs in these cases added to our concern. There have been many instances of Gram-negative outbreaks in neonatal units around the world (Voss et al., 1994; McDonald et al., 1998; Moolenaar et al., 2000). The situation may be further complicated by multiresistant isolates. Such multiresistance in Gram-negative bacteria may be associated with the production of extended-spectrum $\beta$-lactamase (ESBL). Until the mid-1980s, resistance to $\beta$ lactam antibiotics was known to be limited to organisms with inducible chromosomal $\beta$-lactamase genes; this form of resistance is not transmissible. Consequently, it came as an unwelcome surprise when a species of Klebsiella with plasmid-mediated resistance to extended-spectrum cephalosporins was isolated in Germany in 1983, and in the following year, similar resistance in Klebsiella was reported

Abbreviations: ESBL, extended-spectrum $\beta$-lactamase; NICU, neonatal intensive-care unit. from France. It was found that in the former case, the resistance was due to a new $\beta$-lactamase that differed from the enzyme SHV-1 by a single mutation, and was therefore named SHV-2 (Goussard et al., 1991). The enzyme detected in France was named CTX-1, and was found to be a mutant TEM enzyme (Sirot et al., 1987). These enzymes, also called ESBLs, are produced exclusively by Gram-negative bacteria and are active against extended-spectrum cephalosporins, aztreonam, narrow-spectrum cephalosporins and antiGram-negative-bacterium penicillins (Philippon et al., 1989; Jacoby \& Medeiros, 1991). At present, at least 67 TEM-derived and 12 SHV-derived ESBLs have been described (e.g. Jacoby \& Medeiros, 1991; Naumovski et al., 1992). More ESBLs are being added to the list, e.g. SHV-13 (Yuan et al., 2000) and SHV-24 (Kurokawa et al., 2000), and an increasing number of ESBL-producing bacteria is being reported. Neonates are particularly vulnerable to infection, so any delay in the initiation of empirical therapy or wrong choice of antibiotics is to be avoided. Keeping these facts in mind, we designed our study to investigate the prevalence of ESBL-producing Gram-negative rods in septicaemic neonates.

\section{METHODS}

All septicaemic neonates admitted to the NICU of King George's Medical College were prospectively enrolled over a period of 1 year. Blood (1-2 ml) was collected from each patient, and inoculated into 
$5 \mathrm{ml}$ brain heart infusion broth with $0 \cdot 025 \%$ sodium polyanethol sulfonate (Himedia Laboratories). A second sample was collected from a different site after $1 \mathrm{~h}$ to rule out contaminating flora. The broth was incubated aerobically at $37^{\circ} \mathrm{C}$. A blind subculture was done after $18 \mathrm{~h}$; if no growth was obtained, the bottles were examined daily for 7 days. Any sign of growth was followed up by subculture. Media used for subculturing included chocolate agar, 5\% sheep blood agar and MacConkey agar (Himedia Laboratories). Isolates were identified using standard biochemical tests (Collee et al., 1996).

Antimicrobial susceptibility tests. Susceptibility tests were performed using the Kirby-Bauer disc diffusion method and following NCCLS guidelines (National Committee for Clinical Laboratory Standards, 2000). Antimicrobials used were ampicillin (10 $\mu$ g per disc), amoxicillin $(10 \mu \mathrm{g}$ per disc), gentamicin (10 $\mu \mathrm{g}$ per disc), amikacin (30 $\mu \mathrm{g}$ per disc), cefotaxime (30 $\mu \mathrm{g}$ per disc), ceftazidime (30 $\mu \mathrm{g}$ per disc), ciprofloxacin $(5 \mu \mathrm{g}$ per disc), cotrimoxazole ( $1.25 \mu \mathrm{g}$ trimethoprim per disc/23.75 $\mu$ g sulfamethoxazole per disc) and tetracycline (30 $\mu \mathrm{g}$ per disc). The discs were obtained from Himedia Laboratories.

Screening for ESBL. This was done as part of the routine susceptibility testing, according to criteria recommended by the NCCLS. Two discs, ceftazidime $(30 \mu \mathrm{g})$ and cefotaxime $(30 \mu \mathrm{g})$, were used. An inhibition zone of $\leqslant 22 \mathrm{~mm}$ for ceftazidime and $\leqslant 27 \mathrm{~mm}$ for cefotaxime indicated that the strain probably produced ESBL.

Phenotypic confirmatory test for ESBL production. This was done as per NCCLS recommendations, on Mueller-Hinton agar. Four discs, containing cefotaxime $(30 \mu \mathrm{g})$, cefotaxime/clavulanic acid $(30 \mu \mathrm{g} /$ $10 \mu \mathrm{g})$, ceftazidime $(30 \mu \mathrm{g})$ and ceftazidime/clavulanic acid $(30 \mu \mathrm{g} /$ $10 \mu \mathrm{g}$ ), were used. $\mathrm{A} \geqslant 5 \mathrm{~mm}$ increase in zone diameter for either antimicrobial tested in combination with clavulanic acid versus its zone when tested alone confirmed ESBL production. Discs containing clavulanic acid were prepared and stored according to NCCLS guidelines.

\section{RESULTS}

Blood samples for culture were obtained from 728 suspected cases of neonatal septicaemia, of which $346(47.5 \%)$ were positive. The total number of pathogenic isolates was 400 , of which 50 were Candida spp. and 350 were bacterial isolates. Four samples showed polymicrobial growth. The Gramnegative bacterium most commonly isolated was Klebsiella spp. (24.6\%), followed by Enterobacter spp. (22.9\%), Escherichia coli (14.0\%), Pseudomonas spp. (2.9\%), Citrobacter spp. (1.7\%) and Acinetobacter spp. (1.7\%). Thus, $67.7 \%$ of the isolates were Gram-negative rods and the rest comprised Gram-positive bacteria, such as Staphylococcus aureus (14.0\%), coagulase-negative Staphylococcus (16.6\%) and Enterococcus spp. $(1 \cdot 7 \%)$.
All Gram-negative rods were screened and tested for ESBL production. ESBL was detected in $75(87.2 \%)$ isolates of Klebsiella spp., 58 (72.5\%) isolates of Enterobacter spp., 32 $(65.3 \%)$ isolates of E. coli, two (33.3\%) isolates of Acinetobacter spp. and in none of the isolates of Citrobacter or Pseudomonas spp.

When the results of the initial screening test for the three major Gram-negative isolates were compared with the results of the confirmatory test for ESBL (Table 1), it was found that more than $78 \%$ of isolates that were positive in the screening test were also positive by the confirmatory testing. Some of the isolates that were positive in the screening test were negative for ESBL production when tested by the confirmatory method. All isolates that were negative by the screening test were found to be non-ESBL producers by the confirmatory test.

Routine susceptibility testing failed to predict ESBL production in $37.5 \%$ of E. coli, $63.1 \%$ of Klebsiella spp. and $48.0 \%$ of Enterobacter isolates. These strains showed some degree of susceptibility to both cefotaxime and ceftazidime in routine susceptibility testing (Table 2). Most isolates (78.7-94.0 \%) that were resistant to both cephalosporins were ESBL producers, while $5 \cdot 9-21.2 \%$ were not.

Analysis of antimicrobial-resistance patterns (Fig. 1) showed that resistance to $\beta$-lactam and non- $\beta$-lactam agents is more frequent in ESBL-producing strains than in those which did not produce the enzyme.

A follow-up of the culture-proven cases of neonatal septicaemia during their hospital stay revealed that $38 \%$ of the patients died and the rest were discharged after recovery. The death rate was even higher $(46.3 \%)$ with Gram-negative septicaemia (Table 3). More than $60 \%$ of the newborns harbouring ESBL-producing bacteria in their blood expired, as opposed to $35.7 \%$ of those that were infected with nonESBL-producing strains.

\section{DISCUSSION}

The microbiological spectrum of neonatal septicaemia shows marked geographical variations. In tropical areas, early-onset infections may be caused by multiresistant hospital-acquired bacteria, which are transmitted during the perinatal period. These organisms are usually resistant genera of the family

Table 1. ESBL-producing Gram-negative bacilli: screening vs confirmatory test

Percentage of total isolates is given in parentheses.

\begin{tabular}{|c|c|c|c|c|c|c|}
\hline \multirow{2}{*}{$\begin{array}{l}\text { Confirmatory test } \\
\text { result }\end{array}$} & \multicolumn{3}{|c|}{ Isolates positive on screening test } & \multicolumn{3}{|c|}{ Isolates negative on screening test } \\
\hline & E. coli & $\begin{array}{l}\text { Klebsiella } \\
\text { spp. }\end{array}$ & $\begin{array}{c}\text { Enterobacter } \\
\text { spp. }\end{array}$ & E. coli & $\begin{array}{l}\text { Klebsiella } \\
\text { spp. }\end{array}$ & $\begin{array}{c}\text { Enterobacter } \\
\text { spp. }\end{array}$ \\
\hline Positive & $32(78 \cdot 0)$ & $75(87 \cdot 2)$ & $58(78 \cdot 3)$ & 0 & 0 & 0 \\
\hline Negative & $9(21 \cdot 9)$ & $11(12 \cdot 7)$ & $16(21 \cdot 6)$ & $8(100)$ & 0 & $6(100)$ \\
\hline
\end{tabular}


Table 2. Efficacy of routine susceptibility testing in detection of ESBL production

Isolates are defined as resistant if diameter of inhibition zone $\leqslant 14 \mathrm{~mm}$, and as sensitive if diameter of zone $>$ $14 \mathrm{~mm}$. Percentage of total isolates is given in parentheses.

\begin{tabular}{|c|c|c|c|c|c|c|}
\hline \multirow[t]{2}{*}{$\begin{array}{l}\text { Confirmatory test } \\
\text { result }\end{array}$} & \multicolumn{3}{|c|}{$\begin{array}{l}\text { Isolates resistant to either or both } \\
\text { cephalosporins }\end{array}$} & \multicolumn{3}{|c|}{$\begin{array}{l}\text { Isolates sensitive to both } \\
\text { cephalosporins }\end{array}$} \\
\hline & E. coli & $\begin{array}{l}\text { Klebsiella } \\
\text { spp. }\end{array}$ & $\begin{array}{c}\text { Enterobacter } \\
\text { spp. }\end{array}$ & E. coli & $\begin{array}{l}\text { Klebsiella } \\
\text { spp. }\end{array}$ & $\begin{array}{c}\text { Enterobacter } \\
\text { spp. }\end{array}$ \\
\hline Positive & $26(78 \cdot 7)$ & $63(94 \cdot 0)$ & $46(83 \cdot 6)$ & $6(37 \cdot 5)$ & $12(63 \cdot 1)$ & $12(48 \cdot 0)$ \\
\hline Negative & $7(21 \cdot 2)$ & $4(5 \cdot 9)$ & $9(16 \cdot 3)$ & $10(62 \cdot 5)$ & $7(36 \cdot 8)$ & $13(52 \cdot 0)$ \\
\hline
\end{tabular}

Enterobacteriaceae, Pseudomonas spp. and staphylococci (Begue, 1991). The spectrum of bacteria in our hospital is comparable to that of the National Neonatal Perinatal Network Database report. Our most frequent isolates were Klebsiella spp. (24.6\%), in accordance with other Indian studies (Das et al., 1999; Kapoor \& Sumathi, 2000). The prevalence of Enterobacter sepsis was alarming; a report from Pakistan in 1996 expressed concern about increasing Enterobacter sepsis (Bhutta, 1996). The overall incidence of septicaemia confirmed by culture in our laboratory was $47.5 \%$; reports from India and other countries show that the incidence varies between 36 and $55 \%$ (Gaynes et al., 1996; Ako-Nai et al., 1999; Das et al., 1999).

The high percentage of ESBL-producing isolates may be due to the selective pressure imposed by extensive use of antimicrobials in the intensive-care unit. Some earlier reports have quoted a lower prevalence of ESBL-producing isolates, compared to that of the present study (Emery \& Weymouth, 1997; Vercauteren et al., 1997). Distinct regional variations have been detected in the incidence of ESBLproducing isolates, and it is often a local problem (Fluit et al., 1998). A study from central India reported that $76.5 \%$ of Klebsiella isolates resistant to third-generation cephalosporins were ESBL producers, as confirmed by the double-disc synergy test (Hansotia et al., 1997). Another study from southern India reported an incidence of $58.06 \%$ for ESBLproducing E. coli, and $57 \cdot 14 \%$ for ESBL-producing Enterobacter spp. (Ananthakrishnan et al., 2000). In our study, two isolates of Acinetobacter spp. showed the presence of ESBL; as we tested only six isolates, it is difficult to reach any conclusion regarding the ESBL-producing potential of this bacterium. None of the isolates of Pseudomonas spp. were positive for ESBL production by the method we used; whether they were actually non-producers, or whether some of them did produce $\beta$-lactamases that were not inhibited by clavulanate, needs to be investigated. The majority of the isolates positive on screening were confirmed to be ESBL producers, although some were negative for ESBL production by confirmatory testing. It may well be the case that these latter groups could be treated with $\beta$-lactam agents. As opposed to the group that were positive on screening, none of the isolates that were negative on screening behaved otherwise in the confirmatory tests, i.e. all of them were negative for ESBL production by the confirmatory method, as expected. As far as the routine susceptibility test is concerned, the majority of the resistant isolates were ESBL producers, but a large number of those that showed susceptibility to either or both cephalosporins $(37 \cdot 5-63 \cdot 1 \%)$ in the routine susceptibility testing were actually positive in the confirmatory test for ESBL. Many other workers have reported similar results (Thomson \& Sanders, 1992; Sanders et al., 1996). Whilst these strains remain susceptible to cefotaxime or ceftazidime in vitro, there is little doubt that these drugs are rarely successful in treating infections caused by ESBLproducing members of the family Enterobacteriaceae, unless the infection is limited to the urinary tract (Sanders et al., 1996). To sum up the results of the screening and routine susceptibility tests in predicting ESBL production, it is important to mention that for the screening test, negative results are a better guide than positive results. Following all positive results might lead to unnecessary avoidance of conventional $\beta$-lactams in a good number of cases. In the case of routine susceptibility testing, negative predictions are to be taken with caution as a large number of ESBL producers can be missed. This might give disastrous results of uncontrolled septicaemia if treated with $\beta$-lactam agents.

When the antimicrobial-resistance patterns of the isolates were reviewed, we found that among the ESBL producers, more than $74 \%$ were resistant to cefotaxime and up to $59.5 \%$ were resistant to ceftazidime. Cefotaxime was found to be the most common cephalosporin administered to the neonates in our NICU.

All ESBL producers were resistant to ampicillin, more than $44 \%$ to cotrimoxazole, more than $88 \%$ to tetracycline and more than $76 \%$ to gentamicin. Such wide resistance spectra of ESBL producers, including resistance to drugs such as sulfonamides, trimethoprim and aminoglycosides, have been observed by many others (Jett et al., 1995; Villa et al., 2000; Subha et al., 2001). One study reported that ciprofloxacin resistance and ESBL production in Klebsiella pneumoniae are closely associated (Paterson et al., 2000). They found that, globally, $18 \%$ of ESBL producers were resistant to ciprofloxacin. Our results also showed that a greater percentage of ESBL producers than non-producers were resistant to ciprofloxacin. Such a broad resistance spectrum is a 

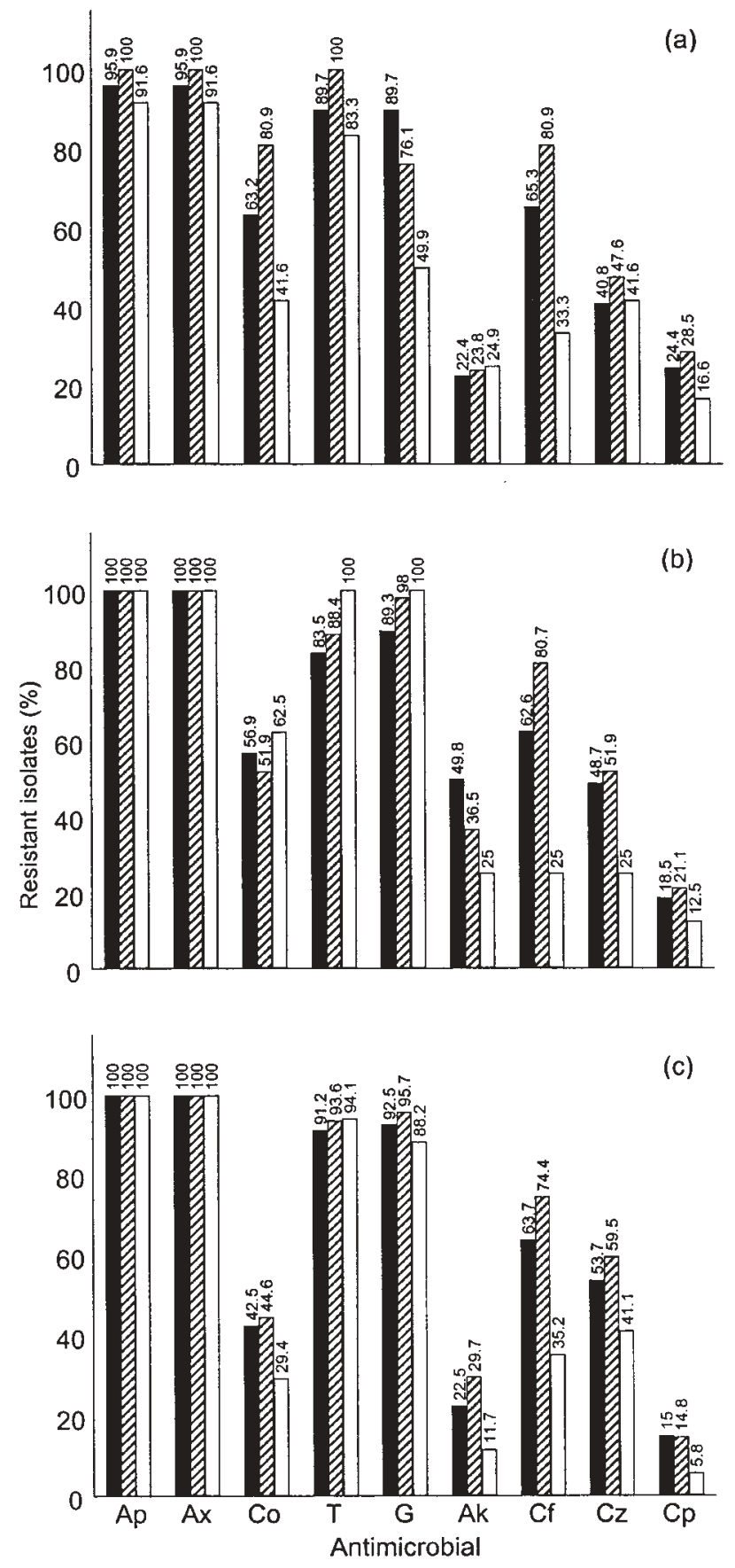

Fig. 1. Antimicrobial-resistance patterns of clinical isolates of: (a) Escherichia coli; (b) Klebsiella spp.; (c) Enterobacter spp. Filled bars represent total resistant organisms, hatched bars represent resistant ESBL producers and open bars represent resistant ESBL nonproducers. Ap, Ampicillin; Ax, amoxicillin; Co, cotrimoxazole; T, tetracycline; G, gentamicin; Ak, amikacin; Cf, cefotaxime; $\mathrm{Cz}$, ceftazidime; Cp, ciprofloxacin.

cause for concern and necessitates the restricted use of extended-spectrum cephalosporins, and a trial of other suitable alternatives. The cost of the antibiotics has always been a limiting factor in therapy planning; keeping this in
Table 3. ESBL production and outcome of Gram-negative neonatal septicaemia

\begin{tabular}{|lcc|}
\hline Outcome & $\begin{array}{c}\text { Cases with isolates } \\
\text { producing ESBL (\%) }\end{array}$ & $\begin{array}{c}\text { Cases with isolates not } \\
\text { producing ESBL (\%) }\end{array}$ \\
\hline Survival & $38 \cdot 7$ & $64 \cdot 2$ \\
Death & $61 \cdot 2$ & $35 \cdot 7$ \\
\hline
\end{tabular}

mind, it is worth noting that in comparison to other antibiotics, resistance to amikacin and ciprofloxacin was less frequent. A recent study has found ciprofloxacin to be highly effective in treating multiresistant Gram-negative infections, including use in premature and extremely low-birth-weight infants (Khaneja et al., 1999). Ciprofloxacin also acts against staphylococci.

In our region, testing for ESBL production is not routinely done by most centres. This may allow the dissemination of ESBL-producing strains within and between hospitals to remain undetected for long periods. The consequence can be serious outbreaks, particularly in the intensive-care units.

The overall mortality rate in neonates with septicaemia is high $(38.0 \%)$ in our NICU (Table 3). It was even higher in cases of Gram-negative septicaemia, particularly the cases from which ESBL-producing isolates were recovered. These patients showed discouraging results with the antimicrobial therapy. Keeping in mind the high prevalence of ESBLproducing bacteria in our NICU, we feel it is extremely important to implement a revised strategy of empirical therapy and to monitor ESBL production routinely in NICU isolates, as well as isolates from other wards. Once the availability of clavulanic acid is ensured, only a simple disc diffusion test will be necessary to screen ESBL production.

\section{REFERENCES}

Ako-Nai, A. K., Adejuyigbe, E. A., Ajayi, F. M. \& Onipede, A. O. (1999). The bacteriology of neonatal septicaemia in Ile-Ife, Nigeria. J Trop Pediatr 45, 146-151.

Ananthakrishnan, A. N., Kanungo, R., Kumar, A. \& Badrinath, S. (2000). Detection of extended spectrum $\beta$-lactamase producers among surgical wound infections and burn patients in JIPMER. Indian J Med Microbiol 18, 160-165.

Begue, P. (1991). Current orientation of antibiotic treatment in neonatal bacterial infection. Bull Soc Pathol Exot 84, 712-720 (in French).

Bhutta, Z. A. (1996). Enterobacter sepsis in the newborn - a growing problem in Karachi. J Hosp Infect 34, 211-216.

Collee, J. G., Miles, R. S. \& Watt, B. (1996). Tests for identification of bacteria. In MacKie \& McCartney's Practical Medical Microbiology, 14th edn, pp. 131-149. Edited by J. G. Collee, A. G. Fraser, B. P. Marmion \& A. Simmons. New York: Churchill Livingstone.

Das, P. K., Basu, K., Chakraborty, P. \& Bhowmik, P. K. (1999). Clinical and bacteriological profile of neonatal infections in metropolitan city based medical college nursery. J Indian Med Assoc 97, 3-5.

Ellner, P. D., Fink, D. J., Neu, H. C. \& Parry, M. F. (1987). Epidemiologic factors affecting antimicrobial resistance of common bacterial isolates. J Clin Microbiol 25, 1668-1674. 
Emery, C. L. \& Weymouth, L. A. (1997). Detection and clinical significance of extended-spectrum $\beta$-lactamases in a tertiary-care medical center. J Clin Microbiol 35, 2061-2067.

Fluit, A. C., Jones, M. E., Schmitz, F. J., Acar, J., Gupta, R. \& Verhoef, J. (2000). Antimicrobial susceptibility and frequency of occurrence of clinical blood isolates in Europe from the SENTRY antimicrobial surveillance program, 1997 and 1998. Clin Infect Dis 30, 454-460.

Gaynes, R. P., Edwards, J. R., Jarvis, W. R., Culver, D. H., Tolson, J. S. \& Martone, W. J. (1996). Nosocomial infections among neonates in highrisk nurseries in the United States. National Nosocomial Infections Surveillance System. Pediatrics 98, 357-361.

Goussard, S., Sougakoff, W., Mabilat, C., Bauernfeind, A. \& Courvalin, P. (1991). An IS1-like element is responsible for high-level synthesis of extended-spectrum $\beta$-lactamase TEM-6 in Enterobacteriaceae. J Gen Microbiol 137, 2681-2687.

Hansotia, J. B., Agarwal, V., Pathak, A. A. \& Saoji, A. M. (1997). Extended spectrum $\beta$-lactamase mediated resistance to third generation cephalosporins in Klebsiella pneumoniae in Nagpur, central India. Indian J Med Res 105, 158-161.

Jacoby, G. A. \& Medeiros, A. A. (1991). More extended-spectrum $\beta$ lactamases. Antimicrob Agents Chemother 35, 1697-1704.

Jett, B. D., Ritchie, D. J., Reichley, R., Bailey, T. C. \& Sahm, D. F. (1995). In vitro activities of various $\beta$-lactam antimicrobial agents against clinical isolates of Escherichia coli and Klebsiella spp. resistant to oxyimino cephalosporins. Antimicrob Agents Chemother 39, 1187-1190.

Kapoor, H., Sumathi, M., Aggarwal, P., Jain, S. D. \& Kaur, J. (2000). Spectrum of bacterial isolates in high risk areas of a tertiary care hospital: 3 year study. Indian J Med Microbiol 18, 166-169.

Khaneja, M., Naprawa, J., Kumar, A. \& Piecuch, S. (1999). Successful treatment of late-onset infection due to resistant Klebsiella pneumoniae in an extremely low birth weight infant using ciprofloxacin. J Perinatol 19, 311-314.

Kurokawa, H., Yagi, T., Shibata, N., Shibayama, K., Kamachi, K. \& Arakawa, Y. (2000). A new SHV-derived extended-spectrum $\beta$-lactamase (SHV-24) that hydrolyzes ceftazidime through a single-aminoacid substitution (D179G) in the $\Omega$-loop. Antimicrob Agents Chemother 44, 1725-1727.

McDonald, L. C., Walker, M., Carson, L., Arduino, M., Aguero, S. M., Gomez, P., McNeil, P. \& Jarvis, W. R. (1998). Outbreak of Acinetobacter spp. bloodstream infections in a nursery associated with contaminated aerosols and air conditioners. Pediatr Infect Dis J 17, 716-722.

Moolenaar, R. L., Crutcher, J. M., San Joaquin, V. H., Sewell, L. V., Hutwagner, L. C., Carson, L. A., Robison, D. A., Smithee, L. M. \& Jarvis, W. R. (2000). A prolonged outbreak of Pseudomonas aeruginosa in a neonatal intensive care unit: did staff fingernails play a role in disease transmission? Infect Control Hosp Epidemiol 21, 80-85.
National Committee for Clinical Laboratory Standards (2000). Performance Standards for Antimicrobial Disk Susceptibility Tests, Approved Standard, 7th edn, document M2-A7. Villanova, PA: NCCLS.

Naumovski, L., Quinn, J. P., Miyashiro, D., Patel, M., Bush, K., Singer, S.B.,Graves,D.,Palzkill,T.\& Arvin, A. M. (1992). Outbreak of ceftazidime resistance due to a novel extended-spectrum $\beta$-lactamase in isolates from cancer patients. Antimicrob Agents Chemother 36, 1991-1996.

Paterson, D. L., Mulazimoglu, L., Casellas, J. M. \& 8 other authors (2000). Epidemiology of ciprofloxacin resistance and its relationship to extended-spectrum $\beta$-lactamase production in Klebsiella pneumoniae isolates causing bacteremia. Clin Infect Dis 30, 473-478.

Philippon, A., Labia, R. \& Jacoby, G. A. (1989). Extended-spectrum $\beta$ lactamases. Antimicrob Agents Chemother 33, 1131-1136.

Sanders, C. C., Barry, A. L., Washington, J. A., Shubert, C., Moland, E. S., Traczewski, M. M., Knapp, C. \& Mulder, R. (1996). Detection of extended-spectrum- $\beta$-lactamase-producing members of the family Enterobacteriaceae with Vitek ESBL test. J Clin Microbiol 34, 2997-3001.

Sirot, D., Sirot, J., Labia, R., Morand, A., Courvalin, P., DarfeuilleMichaud, A., Perroux, R. \& Cluzel, R. (1987). Transferable resistance to third-generation cephalosporins in clinical isolates of Klebsiella pneumoniae: identification of CTX-1, a novel $\beta$-lactamase. J Antimicrob Chemother 20, 323-334.

Subha, A., Ananthan, S. \& Alavandi, S. V. (2001). Extended spectrum beta lactamase production and multidrug resistance in Klebsiella species isolated from children under five with intestinal and extraintestinal infections. Indian J Med Res 113, 181-185.

Thomson, K. S. \& Sanders, C. C. (1992). Detection of extendedspectrum $\beta$-lactamases in members of the family Enterobacteriaceae: comparison of the double-disk and three-dimensional tests. Antimicrob Agents Chemother 36, 1877-1882.

Vercauteren, E., Descheemaeker, P., leven, M., Sanders, C. C. \& Goossens, H. (1997). Comparison of screening methods for detection of extended-spectrum $\beta$-lactamases and their prevalence among blood isolates of Escherichia coli and Klebsiella spp. in a Belgian teaching hospital. J Clin Microbiol 35, 2191-2197.

Villa, L., Pezzella, C., Tosini, F., Visca, P., Petrucca, A. \& Carattoli, A. (2000). Multiple-antibiotic resistance mediated by structurally related IncL/M plasmids carrying an extended-spectrum $\beta$-lactamase gene and a class 1 integron. Antimicrob Agents Chemother 44, 2911-2914.

Voss, A., Melchers, W. J., van den Hurk, P., Bergman, K. A., Verweij, P. E. \& Meis, J. F. (1994). Fingerprinting with the polymerase chain reaction: confirmation of an Enterobacter cloacae epidemic in a neonatal intensive care unit. Immun Infekt 22, 214-217 (in German).

Yuan, M., Hall, L. M. C., Savelkoul, P. H. M., Vandenbroucke-Grauls, C. M. J. E. \& Livermore, D. M. (2000). SHV-13, a novel extendedspectrum $\beta$-lactamase, in Klebsiella pneumoniae isolates from patients in an intensive care unit in Amsterdam. Antimicrob Agents Chemother 44, $1081-1084$. 